\title{
Pulp Response of Anionic Lyophilized Collagen Matrix with or without Hydroxyapatite after Pulpotomy in Dog's Teeth
}

\author{
Léa Assed Bezerra da Silva , Mario Roberto Leonardo a, Paulo Nelson-Filho ${ }^{\text {a*, }}$ \\ Alexandra Sárzyla Medeiros ${ }^{\mathrm{a}}$, Marcos Antonio Rossi ${ }^{\mathrm{b}}$ \\ a Department of Pediatric Dentistry, School of Dentistry of Ribeirão Preto, \\ University of São Paulo, Avenida do Café, s/n, 14040-904 Ribeirão Preto - SP, Brazil \\ ${ }^{\mathrm{b}}$ Department of Pathology, Faculty of Medicine of Ribeirão Preto, University of São Paulo, \\ Av. Bandeirantes, 3900, 14049-900 Ribeirão Preto - SP, Brazil
}

Received: June 1, 2005; Revised: January 12, 2006

\begin{abstract}
The aim of the present study was to evaluate histologically the pulp response of anionic lyophilized collagen matrix with or without hydroxyapatite as a biomaterial pulp-capping agent in pulpotomy of dogs' teeth. Sixty pre-molar roots from three dogs were used. After pulpotomy, the remaining pulp tissue was capped with one of the following materials: Group I (20 roots): anionic lyophilized collagen matrix; Group II (20 roots): anionic lyophilized collagen matrix associated with hydroxyapatite; Group III (10 roots): calcium hydroxide (p.a.) paste in saline; Group IV (10 roots): zinc oxide eugenol cement. After 90 days the animals were killed by anesthetic overdose and the teeth were removed and submitted to histological processing. According to the histopathological results, we concluded that the zinc oxide eugenol cement and anionic lyophilized collagen matrix with or without hydroxyapatite did not present satisfactory pulp response and that calcium hydroxide is the suitable material for pulpotomy.
\end{abstract}

Keywords: collagen, hydroxyapatite, calcium hydroxide, pulpotomy

\section{Introduction}

Pulpotomy is a conservative treatment of the radicular pulp tissue used in deciduous and permanent teeth consisting of the removal of inflammatory coronal pulp tissue at the entrance of the root canal and subsequent placement of a material to protect the radicular remnant. This should preserve vitality of this tissue and stimulate the formation of mineralized tissue restoring pulp tissue function and normal structure.

Pulpotomy is considered biologically ideal when the radicular pulp remains vital and isolated from the coronal chamber by a layer of dentine ${ }^{1,2}$. Among the indicated materials for pulp regeneration, calcium hydroxide is mostly used due to its biological properties, such as stimulation of the formation of a mineralized barrier and bactericide action ${ }^{2,3}$.

New biomaterials are being tested in vitro and in vivo for pulp protection in pulpotomies, most notably the bone morphogenetic proteins (BMPs), osteogenic proteins (OPs), transformation growth factor $\beta$ (TGF- $\beta$ ) and collagen ${ }^{4-8}$.

Collagen was been used for bone repair and reconstruction ${ }^{9-12}$, and associated with growth factors or other extra-cellular components to induce the formation of reparative dentine ${ }^{6}$. Some advantages of the use of collagen are the low immunogenic response ${ }^{13,14}$, availability and abundance in nature, homeostatic effect ${ }^{15,16}$, easy manipulation in different shapes and capacity to form fibers from soluble preparations.

On the other hand, hydroxyapatite is a ceramic biomaterial, biocompatible, osteoconductor and classified as a ceramic composed of calcium phosphate crystals that are similar to the mineral portion of the bone tissue ${ }^{17}$. It acts as a frame for bone tissue growth ${ }^{18}$ and has been indicated for filling bone cavities ${ }^{19}$. Hydroxyapatite is not indicated for pulp protection of human teeth because the formation of a dentine bridge has not been observed ${ }^{20}$. However, its combination with other biomaterials is being amply used.

The association of collagen and hydroxyapatite has been indicated as a collagenic biocompatible biomaterial ${ }^{21,22}$. It has been evaluated in laboratory animals ${ }^{19}$ and in humans $\mathrm{s}^{20,23}$, and indicated for pulp coverage $^{5,20}$, filling of surgical cavities in bone defects ${ }^{19,22}$, guided tissue regeneration ${ }^{24}$ and as a fixing agent for ceramic particles ${ }^{25}$.

In this histopathologic study, we evaluated the pulp response after protection with a collagen matrix associated or not with hydroxyapatite in pulpotomies in dogs' teeth.

\section{Material and Methods}

\subsection{Anionic lyophilized collagen matrix preparation}

The collagen associated or not with hydroxyapatite was produced at the Department of Chemistry and Molecular Physics (São Carlos Chemical Institute, University of São Paulo, USP, Brazil).

The collagen matrix was prepared as previously described ${ }^{26,27}$. The electrically neutral tropocollagen molecule of collagen from the bovine pericardium was chemically modified into a negative molecule at physiological $\mathrm{pH}$. The carboxamide groups of asparagine (Asn) and glutamine (Gln) residues were converted by selective hydrolysis into carboxylic groups in $6 \%$ dimethylsulfoxide aqueous solution $(\mathrm{m} / \mathrm{v})$ in the presence of $\mathrm{Ca}(\mathrm{OH})_{2}$ and $\mathrm{Na}_{2} \mathrm{SO}_{4}, \mathrm{NaCl}, \mathrm{KCl}$ and $\mathrm{CaSO}_{4}$ in alkaline medium during 48 hours. The final concentration of soluble collagen preparation was $0.7 \%(\mathrm{~m} / \mathrm{m})$, determined via hydroxyproline. Characterization of this preparation was performed by electrophoresis in polyacrylamide gel, amino acid analysis, in- 
frared spectroscopy, thermal stability (denaturation temperature and shrinking) and scanning electron and transmission microscopy.

\subsection{Anionic lyophilized collagen/hydroxyapatite preparation}

The synthetic hydroxyapatite ceramic used was composed of $\mathrm{Ca}\left(\mathrm{NO}_{3}\right)_{2} .4 \mathrm{H}_{2} \mathrm{O}$ and $\left(\mathrm{NH}_{4}\right)_{2} \mathrm{PO}_{4}$. The powder was divided into $64 \mu$ particles, filtered and dried at $90^{\circ} \mathrm{C}^{28}$. The anionic collagen used for the paste was obtained using 20:1 hydroxyapatite and homogenized collagen and $4.8 \%$ ciprofloxacin of the compound mass. The material was lyophilized and reorganized by the addition of PBS (1:1 on a mass base) as previously described ${ }^{29}$. The anionic collagen matrix and anionic collagen/hydroxyapatite were sterilized in ethylene oxide.

\subsection{Operative procedures}

The second and third maxillary premolars and second, third and fourth mandibular premolars of three mongrel dogs (both sexes; age: 12-18 months; weight: $8-15 \mathrm{Kg}$ ), totaling 30 teeth (60 roots), were radiographed and selected for treatment. Two $\mathrm{mL}$ of Rompum (dihydrothizine chlorhydrate, Bayer S/A, SP, Brazil) was administered i.m. for pre-anesthesia $(3.0 \mathrm{mg} / \mathrm{Kg}$ body weight). The animals were then anesthetized intravenously with $3 \%$ sodium thiopental $(30 \mathrm{mg} / \mathrm{Kg}$ body weight; Thionembutal, Abbot Laboratories, São Paulo, SP, Brazil) and maintained with an isotonic sodium chlorate solution with $2.5 \%$ glucose. Local complementary infiltrate anesthesia was also performed.

Crowns were cleaned, a rubber dam was placed and antisepsis with $2 \%$ chlorhexidine was performed. Coronal access on the occlusal surface was performed with high-speed \#1013 and \#1015 spherical diamond burs with cooling.

After new antisepsis, the pulp chamber was irrigated with sterile saline followed by coronal pulp removal with sterile curettes until the root canal entrance. Homeostasis was obtained by irrigation of the pulp with saline solution, followed by compensating wear with a low-speed Endo Z bur, and final irrigation with saline for dentine chip removal.

Because all variables should be tested in the same animal and in the different quadrants, each hemiarch was submitted in an alternate manner to the experimental protocols.

The pulp tissue was covered with either collagen matrix (Group I, 20 roots) or collagen matrix associated with hydroxyapatite (Group II, 20 roots). The materials from Group I and II were sectioned in slices of approximately $2 \mathrm{~mm}$ diameter with a \#15 blade on a glass plaque, under aseptic conditions and adapted over the pulp tissue. In Group III (10 roots), calcium hydroxide p.a. paste (Merck) mixed with saline (Glicolabor Ind. Farm. Ltda., Ribeirão Preto-SP) in a clinical consistence was used, and in Group IV (10 roots) zinc oxide and eugenol cement (S.S. White Artigos Dentários Ltda., Rio de Janeiro, RJ), manipulated according to manufacturer instructions was used.

In the 4 groups, the teeth were restored with silver amalgam condensed over a zinc phosphate cement base. Ninety days after the surgical procedure, the animals were killed by anesthetic overdose.

\subsection{Histologic processing}

The maxillas and mandibles were removed, dissected and sectioned to obtain individual roots. The roots were fixed in glutaraldehyde, sacarose and sodium cacodylate, and demineralized in EDTA, glutaraldehyde and sodium hydroxide activated by a microwave oven (Sharp, São Paulo, SP, Brazil). The roots were then washed in running water for 24 hours, dehydrated by increasing concentrations of ethyl alcohol, cleared in xylol, and embedded in paraffin blocks. Serial $6-\mu \mathrm{m}$ wide longitudinal sections were stained with hematoxylin and eosin, Mallory Trichrome, Masson Trichrome, and Brown and Brenn.
During the histopathological analysis, the following parameters were evaluated and the subjective qualiquantitative results were graded according to a numerical scale: a) intensity of inflammatory infiltrate: grade 1, absent, grade 2, mild; grade 3, moderate; grade 4 , severe; b) type of inflammatory infiltrate: acute or chronic; c) thickness of the periodontal ligament: grade 1, normal; grade 2, slightly increased, grade 3, moderately increased; grade 4, severely increased; d) cementum resorption: grade 1, absent; grade 2, present; e) dentine resorption: grade 1, absent; grade 2, present; f) bone resorption: grade 1, absent; grade 2, present; g) dentine bridge: grade 1, present; grade 2, absent; and g) periapical region: grade 1, normal; grade 2, altered. The histopathological analysis was performed by one examiner who was blinded to the group being evaluated.

The results were analyzed statistically by the Mann-Whitney nonparametric test using GMC7.7 software (http://www.forp.usp. br/restauradora/gmc/gmc.html).

\section{Results}

\subsection{Group I, collagen matrix (experimental)}

After 90 days, there was no dentine bridge formation in the 20 roots of this group. In 13 roots, the pulp remnant showed tissue degeneration in the cervical third with necrotic apical pulp (when present) (Figures 1 and 2), and the presence of abscess with bacteria in 5 specimens.

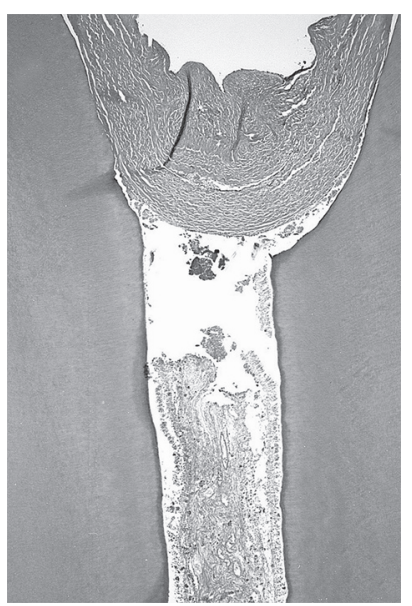

Figure 1. Group I (collagen). Absence of dentine bridge and degenerated pulp remnant in cervical third. HE; magnification, X24.

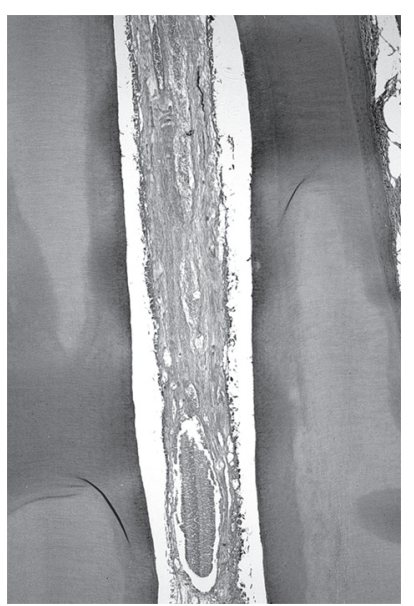

Figure 2. Group I (collagen). Detail of Figure 1. Middle third with tissue degeneration, fibrosis and areas of necrosis. HE; magnification, X40. 
In the pulp there was inflammatory infiltrate predominantly mixed and mild in 13 cases, and moderate and severe in 4 and 3 specimens, respectively. Resorption areas on the surface of the root cementum with no cementoblasts were observed in all specimens (Figure 3). Between the fibers from the apical cementum there was a constant presence of inflammatory cells. In 8 roots, the alveolar bone presented active resorption areas, lack of osteoblasts and in some specimens, osteoclasts in its surface. No dentine resorption occurred in any specimen. The periodontal ligament was mildly increased in 10 specimens, moderately increased with a predominance of neutrophils in 7 and severely increased in 3. In this region, bacteria (cocci and bacilli) were present along the cavity walls, dentine tubules and interstitial connective tissue. In 3 roots in which there was fibrous bridge formation, the pulp tissue, periapical region and alveolar bone were normal.

\subsection{Group II, collagen/hydroxyapatite (experimental)}

In this group (20 roots), a dentine bridge was absent in all specimens. The pulp tissue was fibrotic and there were areas of necrosis in several specimens. In 10 roots, the periapical region presented mononuclear inflammatory cells in mild intensity. In 7 specimens, the inflammatory infiltrate was moderate and in 3 severe with accentuated vascular proliferation and an abscess in 4 roots. In 11 roots, non-repaired resorption areas in the apical cementum were observed with few cementoblasts on the surface. Alveolar bone resorption was observed in 9 roots and no dentine resorption occurred in any specimen. The periodontal ligament was normal or slightly thickened in 6 roots, moderately thickened in 11 and severely thickened in 3 specimens (Figures 4-6).

\subsection{Group III, calcium hydroxide (control)}

In the 10 roots from this group, there was a dentine bridge obliterating the exposed pulp area at the root canal entrance. Adjacent to the dental bridge, the connective tissue was normal and no inflammatory cells were found in any specimen. In all roots, the pulp connective tissue was normal, highly vascularized and with fibroblasts. The apical surface was also intact, with cementocytes throughout the root. The periodontal ligament, composed of dense vascularized connective tissue was of normal thickness and there was no inflammatory infiltrate in any specimen. There were no areas of alveolar bone resorption and there were osteoblasts on its surface and osteocytes in its interior (Figures 7 and 8).

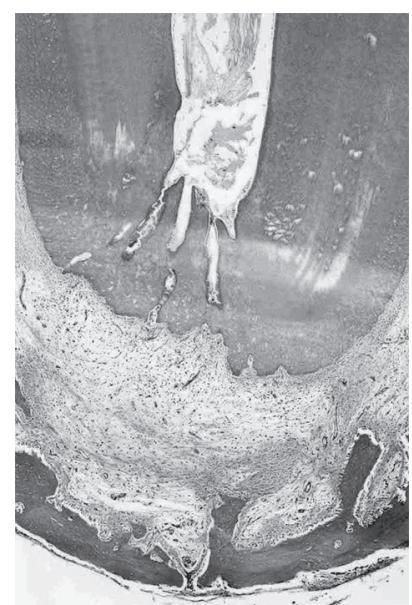

Figure 3. Group I (collagen). Root apex with evident areas of cementum resorption. Severely widened periodontal ligament space, with the presence of inflammatory infiltrate. HE; magnification, X24.

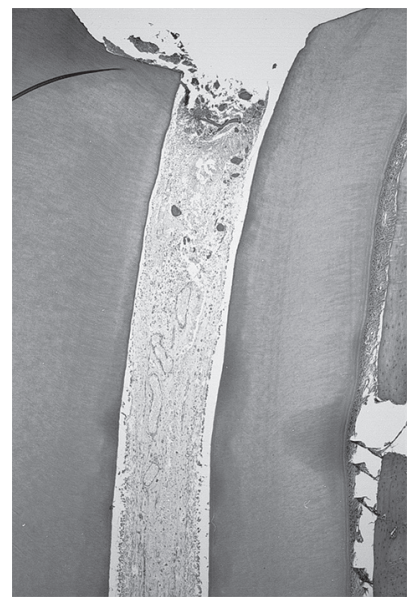

Figure 4. Group II (collagen/hydroxyapatite). Absence of dentine bridge and degenerated pulp tissue. HE; magnification X24.

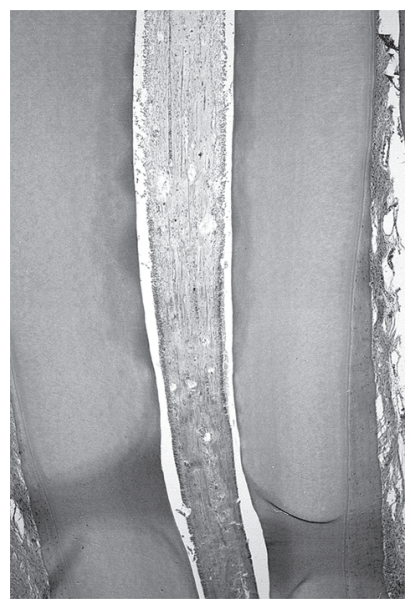

Figure 5. Group II (collagen/hydroxyapatite). Middle third with fibrous pulp tissue and severe hemorrhage. HE; magnification X40.

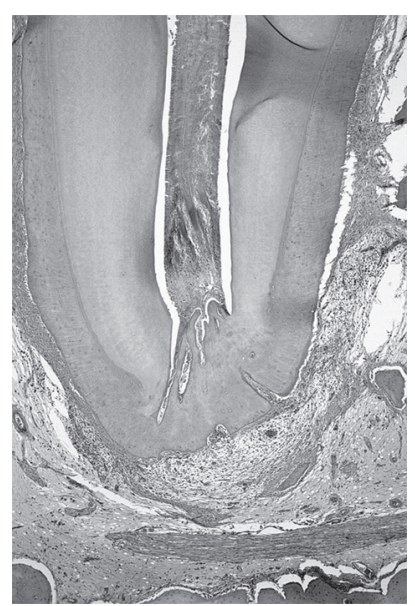

Figure 6. Group II (collagen/hydroxyapatite). Root apex with areas of cementum resorption. Moderately increased periodontal ligament thickness, with the presence of moderate inflammatory cells infiltrate. HE; magnification X24. 


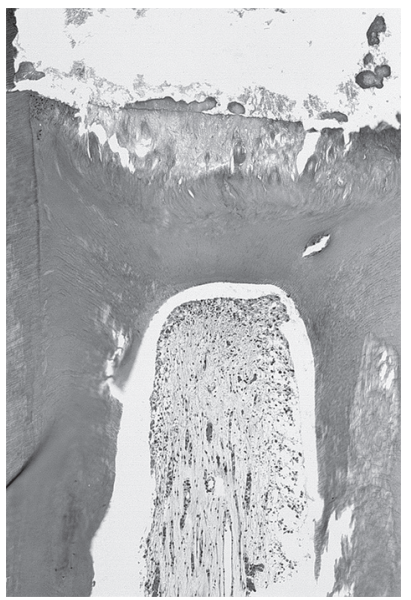

Figure 7. Group III (calcium hydroxide). Dentine bridge in direct contact with the pulp-capping material. Integral pulp tissue. HE; magnification X24.

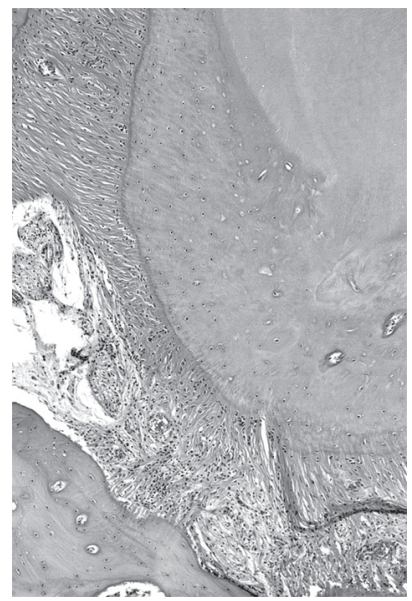

Figure 8. Group III (calcium hydroxide). Apical and periapical regions showing the periodontal ligament with normal thickness and absence of inflammatory cells infiltrate. HE; magnification X24.

\subsection{Group IV, Zinc oxide and eugenol (control)}

None of the 10 evaluated roots presented a dentine bridge and there was pulp tissue necrosis and abscess. The apical cementum was irregular due to extensive resorption in all samples. There was no dentine resorption in any root. The periodontal ligament was moderately thickened in all specimens. The inflammatory infiltrate was moderate in 8 specimens, with the predominance of neutrophils and absent/mild in 2 specimens. In most specimens, there were non-repaired resorption areas and a reduced presence of osteoblasts in the alveolar bone (Figure 9).

The numerical results of the histopathologic analysis are reported in Table 1.

\subsection{Statistical analysis}

The inflammatory infiltrate, the thickness of the periodontal ligament, resorption of mineralized tissues, periapical area and dentine bridge were statistically similar for Groups I, II and IV ( $p>0.05)$ and different for Group III ( $\mathrm{p}<0.05)$.

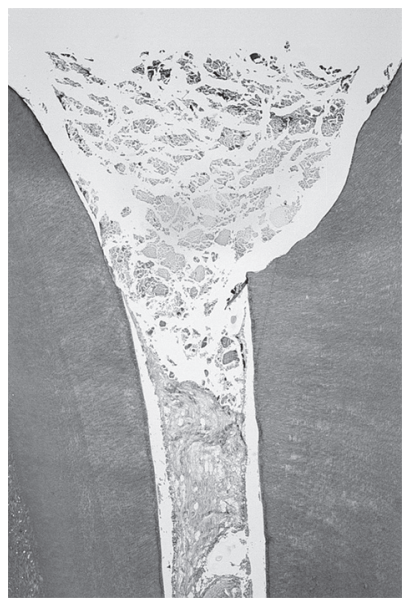

Figure 9. Group IV (zinc oxide eugenol). Absence of dentine bridge. Degenerated pulp tissue. HE; magnification X24.

Table 1. Results of the histopathologic analysis.

\section{Parameters}

\section{Materials}

Collagen matrix Collagen + hydroxyapatite Calcium hydroxide Zinc oxide and eugenol (Group I)

\begin{tabular}{|c|c|c|c|c|c|}
\hline & & (Group 1) & (Group II) & $($ Group III)* & (Group IV) \\
\hline \multirow{4}{*}{ Inflamatory infiltrate } & Absent & 0 & 0 & 10 & 0 \\
\hline & Mild & 13 & 10 & 0 & 2 \\
\hline & Moderate & 4 & 7 & 0 & 8 \\
\hline & Severe & 3 & 3 & 0 & 0 \\
\hline \multirow{4}{*}{$\begin{array}{l}\text { Thickness of } \\
\text { periodontal ligament }\end{array}$} & Normal & 0 & 0 & 10 & 0 \\
\hline & Slightly increased & 10 & 6 & 0 & 2 \\
\hline & Moderately increased & 7 & 11 & 0 & 8 \\
\hline & Severely increased & 3 & 3 & 0 & 0 \\
\hline \multirow{3}{*}{$\begin{array}{l}\text { Mineralized tissue } \\
\text { resorption }\end{array}$} & Cementum & 20 & 11 & 0 & 8 \\
\hline & Dentine & 0 & 0 & 0 & 0 \\
\hline & Bone & 8 & 9 & 0 & 2 \\
\hline \multirow[t]{2}{*}{ Dentine bridge } & Present & 0 & 0 & 10 & 0 \\
\hline & Absent & 20 & 20 & 0 & 10 \\
\hline \multirow[t]{2}{*}{ Periapical region } & Normal & 3 & 0 & 10 & 2 \\
\hline & Altered & 17 & 20 & 0 & 8 \\
\hline
\end{tabular}

Values are reported as number of roots. *p $<0.05$, Group III was statistically different in all parameters evaluated from Groups I, II, and IV, which were statistically similar. 


\section{Discussion}

In humans, the biological effect of pulp protection materials is evaluated fundamentally by the response of the pulp tissue and the periapical tissue after the use of these materials.

The acellular polyanionic collagen material used in this study is a biomaterial characterized by Bet et al. ${ }^{26}$ in 2001, and prepared by the selective and controlled hydrolysis of carboxyamides from asparagine and glutamine residues of type I collagen present in pericardium from bovine origin.

The wide use of collagen in the field of biomaterials is associated to natural properties that include the low immune response, even when from heterologous sources, low toxicity, the ability to promote cellular growth and attachment, homeostasis ${ }^{30}$ and the ability of collagen solutions to reconstitute in vitro into the microfibrillar structure found in natural tissues. It is used in a variety of physical forms as an hemostatic agent, for soft tissue augmentation, burn and wound dressing $^{30,31}$, peripheral nerve growth support ${ }^{32}$, in the treatment of furcation lesions ${ }^{21}$ and in bone defect healing ${ }^{27}$, among others.

A collagen matrix acts as a molecular grid with channels and pores, which changes the original dense collagen structure of bovine pericardium into a sponge-like structure allowing cell migration. The compact material needs to be reabsorbed for repair, which extends this process ${ }^{19}$. The pore size is associated with the interconnection between them, which increases with larger pores, allowing tissue migration to the implant interior. The collagen matrix used in rat tibia bone defects, independent of pore size, has continuous and interconnected pores similar to collagen. The efficiency of this structure allows early cellular migration. In bone tissue, this material is considered to be biocompatible and an osteoconductor, indicating that it is a promising material for cases in which bone formation is necessary, particularly in periodontics and minor oral surgeries ${ }^{12}$. Contrary to the results obtained in bone, neither collagen matrix resorption nor the formation of mineralized tissue occurred in pulp tissue in the present study.

Some authors ${ }^{4,5}$ report that mineralized tissue formation over the pulp tissue is due to the infiltration of mesenchymal pulp cells in the collagen pores determining dentine juxtaposition. Another possible mechanism would be that the collagen fibers catalyze the crystallization of calcium phosphate, in physiological concentration of calcium and phosphate ions. Also, the formation of the collagen frame in three dimensions is recognized by the cells as a frame for the initial repair process, similar to the fibrin coagulum observed in normal tissue repair, leading to dentine repair without tissue necrosis ${ }^{4}$.

The results of the pulp tissue of Groups I (collagen matrix) and II (collagen/hydroxyapatite) did not agree with the literature, because a mineralized dentine bridge did not occur after direct pulp protection with these materials. The pulp tissue did not remain vital after protection leading to pulp fibrosis accompanied by cellular death, which was a frequent finding with these two materials in this study.

Our results cannot be compared to other studies due to the lack of research on the use of the association collagen/hydroxyapatite with pulp tissue. The results of the calcium hydroxide and zinc eugenol groups were similar to the results found in the literature ${ }^{1,33}$, i.e., calcium hydroxide preserved pulp remnant vitality and favored the formation of a mineralized tissue barrier. Histologically similar to other studies ${ }^{34,35}$, zinc oxide and eugenol in pulp tissue led to an inflammatory reaction varying from chronic to acute suppurative pulpitis, with the presence of lymphocytes and polymorphonuclear cells.

\section{Conclusion}

The collagen matrix associated or not with hydroxyapatite was not biocompatible and did not present dentinogenic capacity after pulpotomy in dogs. Among the tested materials, only calcium hydroxide can be indicated for pulpotomies.

\section{Acknowledgments}

The authors thank Dr. Gilberto Goissis (Department of Chemistry and Molecular Physics - São Carlos, Chemical Institute, Universisty of São Paulo (USP), Brazil, for providing the collagen matrix and the collagen associated with hydroxyapatite. The authors thank FAPESP (process number 99/03467-8) for the financial support.

\section{References}

1. Assed S, Leonardo MR, Silva LAB, Nelson-Filho P, Pinto DMG. Calcium hydroxide pulpotomy in young permanent teeth with periapical involvement. Brazilian Endodontic Journal. 1997; 2(1):38-42.

2. Ranly DM. Pulpotomy therapy in primary teeth: new modalities for old rationales. Pediatric Dentistry. 1994; 16(6):403-409.

3. Leonardo MR, Silva LAB, Leonardo RD, Utrilla LS, Assed S. Histological evaluation of therapy using a calcium hydroxide dressing for teeth with incompletely formed apices and periapical lesions. Journal of Endodontics. 1993; 19(7):348-352.

4. Dick HM, Carmichael DJ. Reconstituted antigen-poor collagen preparations as potential pulp-capping agents. Journal of Endodontics. 1980; 6(7):641-644.

5. Nevins AJ, La Porta RF, Borden BG, Spangberg LS. Pulpotomy and partial pulpectomy procedures in monkey teeth using cross-linked collagen-calcium phosphate gel. Oral Surgery, Oral Medicine and Oral Pathology. 1980; 49(4):360-365.

6. Nakashima M. Induction of dentine in amputated pulp of dogs by recombinant human bone morphogenetic proteins-2 and -4 with collagen matrix. Archives of Oral Biology. 1994; 39(12):1085-1089.

7. Jepsen S, Albers HK, Fleiner B, Tucker M, Rueger D. Recombinant human osteogenic protein-1 induces dentin formation: an experimental study in miniature swine. Journal of Endodontics. 1997; 23(6):378-382.

8. Melin M, Joffre-Romeas A, Farges JC, Couble ML, Magloire H, Bleicher F. Effects of TGF $\alpha 1$ on dental pulp cells in cultured human tooth slices. Journal of Dental Research. 2000; 79(9):1689-1696.

9. Pachence JM. Collagen-based devices for soft tissue repair. Journal of Biomedical Materials Research. 1996; 33(1):35-40.

10. Delbalso AM, Adrian JC. Collagen gel in osseous defects: a preliminary study. Oral Surgery, Oral Medicine and Oral Pathology. 1976; 42(5):562569.

11. Mitchell R. An evaluation of bone healing in cavities in the jaws implanted with a collagen matrix. The British Journal of Oral \& Maxillofacial Surgery. 1992; 30(3):180-182.

12. Rocha LB, Goissis G, Rossi MA. Biocompatibility of anionic collagen matrix as scaffold for bone healing. Biomaterials. 2002; 23(2):449456.

13. DeLustro F, Smith ST, Sundsmo J, Salem G, Kincaid S, Ellingsworth L. Reaction to injectable collagen: results in animal model and clinical use. Plastic and Reconstructive Surgery. 1987; 79(4):581-594.

14. Kamer FM, Churukian MM. Clinical use of injectable collagen: a three year retrospective review. Archives of Otolaryngology. 1984; 110(4):93-98.

15. Watson SP. Collagen receptor signalling in platelets and megakaryocytes. Thrombosis and haemostasis. 1999; 82(2):365-76.

16. Chiang TM. Collagen-platelet interaction: platelet non-integrin receptors. Histology and Histopathology. 1999; 14(2):579-585.

17. Legeros RS. Calcium phosphate materials in restorative dentistry: a review. Advances in Dental Research. 1988; 2(1):164-180.

18. Tenhuisen KS, Martin RI, Klimkiewicz M, Brown PW. Formation and properties of a synthetic bone composite: hydroxyapatite-collagen. Journal of Biomedical Materials Research. 1995; 29(7):803-810.

19. Gabrielli MAC, Marcantonio-Junior E, Goissis G, Okamoto T, Gagrielli MFR, Vieira EH. Hydroxylapatite implants with or without collagen in 
the zygomatic arch of rats. Histological study. Brazilian Dental Journal. 2001; 12(1):9-15.

20. Subay RK, Asçi S. Human pulpal response to hydroxyapatite and a calcium hydroxide material as direct capping agents. Oral Surgery, Oral Medicine and Oral Pathology. 1993; 76(4):485-492.

21. Cirelli JA, Marcantonio-Junior E, Marcantonio A R, Marcantonio RAC, Lia ARCC, Goissis G, Rossa-Junior RC. Evaluation of anionic collagen membranes in the treatment of class II furcation lesions: an histometric analysis in dogs. Biomaterials. 1997; 18(18):1227-1234.

22. Kikuchi M, Itoh S, Ichinose S, Shinomiya K, Tanaka J. Self-organization mechanism in a bone-like hydroxyapatite/collagen nanocomposite synthesized in vitro and its biological reaction in vivo. Biomaterials. 2001; 22(13):1705-1711.

23. Mehlisch DR, Taylor TD, Leibold DG, Hiatt R, Waite DE, Waite PD, Laskin DM, Smith ST, Koretz MM. Evaluation of collagen/hydroxylapatite for augmenting deficient alveolar ridges: a preliminary report Journal of Oral and Maxillofacial Surgery. 1987; 45(5):408-413.

24. Rego DM, Marcantonio-Junior E, Lia RCC, Goissis G. Evaluation of a collagen membrane in dogs periodontium. Histological analysis. Journal of Dental Research. 1994; 73(4):764.

25. Gongloff RK, Montogomery CK. Experimental study of the use of collagen tubes for implantation of particulate hydroxyapatite. Journal of Oral and Maxillofacial Surgery. 1985; 43(11):845-849.

26. Bet MR, Goissis G, Lacerda CA. Characterization of polyanionic collagen prepared by selective hydrolysis of asparagine and glutamine carboxyamide side chains. Biomacromolecules. 2001; 2(4):1074-1079.
27. Rocha LB, Brochi MAC, Bellucci AD, Rossi MA. Efficacy of polyanionic collagen matrices for bone defect healing. Journal of Biomedical Materials Research. Part B, Applied Biomaterials. 2004; 71(2):355-359.

28. Jarcho M, Bolen CH, Thomas MB, Bobick J, Kay JF, Doremus RH. Hydroxyapatite synthesis and characterization in dense polycrystalline form. Journal of Materials Science. Materials in Medicine. 1976; 11(11):2027-2035.

29. Martins VCA, Goissis G, Ribeiro AC, Marcantonio-Júnior E, Bet MR. The controlled release of antibiotic by hydroxyapatite: anionic collagen composites. Artificial Organs. 1998; 22(3):215-221.

30. Albee FH. Studies in bone growth. Triple calcium phosphate as a stimulus to osteogenesis. Annals of Surgery. 1920; 71:32-36.

31. Alberius P. Role of osteopromotion in experimental bone grafting to the skull: a study in adult rats using a membrane technique. Journal of Oral and Maxillofacial Surgery. 1992; 50(8):829-834.

32. Anselme K. Osteoblast adhesion on biomaterials. Biomaterials. 2000; 21(7):667-681.

33. Rangel S, Leonardo MR, Silva LAB, Assed S, Nelson-Filho P. Evaluacion clinica y radiografica de dientes deciduos sometidos a la tecnica de pulpotomia hidroxido de calcio. Vida y Salud. 1998; 5(2):18-21.

34. Watts A, Paterson RC. Pulpal response to a zinc oxide-eugenol cement. International Endodontic Journal. 1987; 20(2):82-86.

35. Holland R, Mello W, Souza V, Nery MJ, Bernabé PF, Otoboni FJA. The influence of the sealing material in the healing process of inflammed pulps capped with calcium hydroxide or zinc oxide-eugenol cement. Acta de Odontologia Pediatrica. 1981; 2(1):5-9. 